\title{
Jeff Bluestone steps from bench to bedside to chief academic officer
}

1. mmunologist Jeff Bluestone (Figure 1) has recently been named the Executive Vice Chancellor and Provost of the University of California, San Francisco. Bluestone recently took some time to talk to the JCI about his transition from a pure academic research career.

JCI: Given the current state of the economy, some might think it a rather daunting task to take on the position of Executive Vice Chancellor and Provost at UCSF.

Bluestone: Sure, it is always difficult to enter a situation with the financial challenges that exist today in academic research and education. But when else is a better time to step up and take the risk? Frankly, the financial concerns ranked far behind my conflicted feelings regarding giving up the leadership of the Immune Tolerance Network (ITN) and the UCSF Diabetes Center.

JCI: What will your major goals be for changing UCSF?

Bluestone: I don't see my major goal as "changing” UCSF. That would be presumptuous. The turn in the economy has had devastating effects on students, encumbered us with unfunded and under-funded mandates, and has led to a loss of morale. These problems are exacerbated by a growing chasm between the cost of performing first-rate research and the NIH budget. The decreased funding level is having a sobering effect on the careers of our young investigators. My first job as EVCP is to help the chancellor stabilize the enterprise and navigate this tough period.

Next, I will focus on the research enterprise. It is imperative that when we look back, this next decade be remembered for the tremendous changes in understanding human diseases brought on by the genomic revolution, not the health care battles or NIH budget cuts. We need to develop new ways to bridge the extraordinary basic research with the clinical enterprise. The ITN taught me that some of the best science occurs at the bedside and that the biotech and pharmaceutical industry has tremendous resources that can be brought to bear on the biologic and clinical problems.

Finally, I see my role as helping to bring out the best in UCSF faculty and staff. The goal is to make sure that our customers, the faculty and staff at UCSF, have the resources they need to be successful.

JCI: Any concerns about being a $\mathrm{PhD}$ in a traditionally MD-led role?
Bluestone: Not for a second. Arthur Weiss, $\mathrm{MD}, \mathrm{PhD}$, and I once gave a joint lecture about $\mathrm{T}$ cells and autoimmune disease. Art spoke of T cell signaling; I talked about the treatment of patients with type 1 diabetes using anti-CD 3 mAbs. He told me that my research and thought process as it related to clinical disease was like an MD's. Seriously,

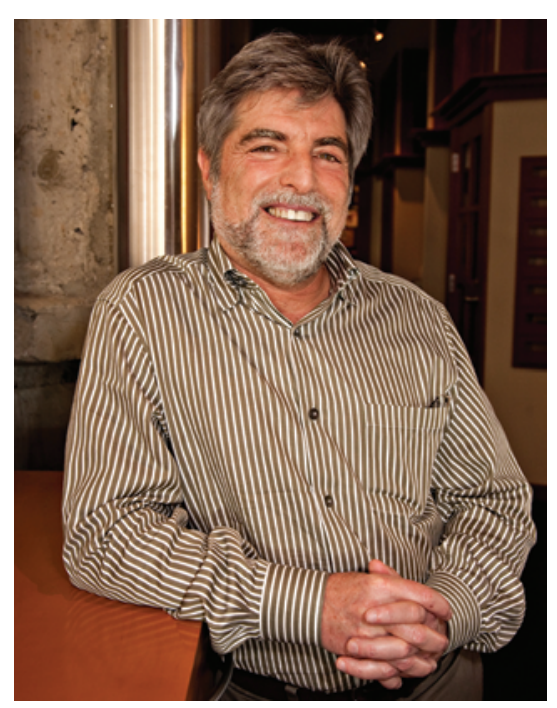

Figure 1

Bluestone moves up at UCSF.

I believe that the success of academic medicine will be team efforts where astute clinicians and $\mathrm{PhD}$ researchers work together to tackle the research problems of our day; success cannot be achieved with either community working in isolation.

JCI: Are you keeping a lab running?

Bluestone: Absolutely. I can't imagine giving up the efforts that have fueled my passion for science and driven my career over the past three decades. The challenge of thinking of ideas with mentees and colleagues and seeing it translated into data that leads to changes in our understanding of how the immune system works still keeps my juices flowing. Can I do it? I hope so.

JCI: What has been the most rewarding part of your research?

Bluestone: Three things: First is watching the trainees grow and become independent and successful. I have been fortunate in my career to have had an outstanding cadre of folks pass through my lab. Second is seeing the efforts in the lab translate into drugs that are being used to treat human disease. I hope that our early work on anti-CD3 and CTLA4-Ig has had something to do with their success in the clinic. I recall the challenges to our early work in CTLA-4 as a negative regulator and the satisfaction to see its development as a treatment for cancer. Finally, I am honored to have been able to direct the ITN and see the opportunities that the organization has had to develop tolerogenic therapies in humans.

JCI: Will you need to reduce your commitment to the ITN? In your view, what are the major accomplishments of the ITN so far?

Bluestone: I have stepped down as Director and turned over the reins to three great translational researchers: Jerry Nepom (Benaroya) will be the new Director; Larry Turka (Harvard) will be the Deputy Director in charge of mechanistic assays and data analysis; and Bill St. Clair (Duke) will be Deputy Director of Clinical Trials.

The ITN is still a work in progress, but I believe that we have made some tangible contributions. There have been several successful trials in studying tolerance, including support of mixed chimerism trials in kidney transplantation, drug withdrawal trials in liver transplantation, and drug therapy trials in ANCA+ vasculitis, allergy, and type 1 diabetes. In all cases, we have been able to demonstrate that short-term treatment with pro-tolerogenic immunotherapies can lead to lasting immune modulatory effects. In addition, the ITN has several ongoing trials looking at peanut allergy and Treg-promoting therapies and has conducted several biomarker studies that will be instrumental in defining tolerance when it is achieved.

JCI: I have heard from your colleagues that you are a legendary multi-tasker. Now that you have only a single job, what will you do with all your extra time?

Bluestone: First of all, I will still run my lab. Second, just because it is one job, there are two titles (Executive Vice Chancellor and Provost). There are 20 direct reports and I cover the whole research and education enterprise at UCSF. I also will stand in for the Chancellor when she is not available. I think I'll be pretty busy!

\section{Ushma S. Neill}

